\title{
Research on the Relation between Real Economy and Virtual Economy
}

\author{
Ran Wei \\ Central University of Finance and Economics, School of Economics, Haidian District, Beijing, China.
}

Received: 08 Nov 2020; Received in revised form: 16 Dec 2020; Accepted: 25 Dec 2020; Available online: 30 Dec 2020

C2020 The Author(s). Published by Infogain Publication. This is an open access article under the CC BY license

(https://creativecommons.org/licenses/by/4.0/).

\begin{abstract}
In the middle and late of last century, the world economy shows indication that developed from real to virtual. The status and share of virtual economy in modern economy are rising constantly. How to make virtual economy to serve real economy effectively is an important issue that the international community pays attention to. China's economy is under influence of the tide of internationalization. The virtual economy has been expanding rapidly in recent years, while the surface is satisfactory and the essence is worrying. In combination with actual situation in China, this paper studies the relationship between virtual economy and real economy in China by vector autoregressive method. The results show that with the development of virtual economy, its influence on the structure of real economy will be stronger and stronger, while the promotion to the growth of real economy will be smaller and smaller. The virtual economy of China has a considerable crowding out effect on real economy.
\end{abstract}

Keywords-Real Economy, Virtual Economy, Vector Autoregression.

\section{INTRODUCTION}

In the background of the rapid expansion of global financial assets, China's virtual economy has also developed rapidly. Capital financialization is becoming a new trend of China's capital development in the future. With the reform of finance, the industry has changed from reality to falsity, and the industrial structure and the industrial organization of China have also changed profoundly, which is embodied in the development of China's financial assets. China's financial industry has embarked on a journey of reform amid financial consolidation and crisis response. The types and numbers of financial institutions have increased dramatically, and the scale of financial assets has expanded at an alarming rate, which is also prominent in the whole world. First, China's big banks, as representative, are playing an increasingly important role in the global banking system with a marked increase in international competitiveness. The number of Chinese companies entering the Fortune 500 in the past five years has also increased, making it the second-largest legion after the United States, and the thirdlargest is Japan, which has been a big lead in China, according to a data from 2013-2017 Fortune 500 list in Fortune China. From 95 companies in the top 500 in 2013 to about a five increasing each year, there were 117 by 2017, and the number was just less than that of the US, and shows a surpass. The 117 Chinese companies that entered the top 500 in 2017 were counted, marking 17 Chinese financial companies (see Table1). According to the table above, the total operating income of 17 domestic financial enterprises is $\$ 120,450,9.1$ million, which plays an important role in the world financial system. In other 
financial sectors, China is moving toward the heart of the global financial system. By the end of 2017, Chinese stocks had a market value of 56.62 trillion yuan, the second-largest in the world. At the same time, China's bond market has also developed rapidly, with the bond custodian balance rising from 418.4 billion yuan at the end of 1997 to 74.0 trillion yuan at the end of 2017, an increase of 176 times to become the world's third largest bond market. Third, the scale of the insurance industry has expanded substantially. By the end of 2017, China's insurance industry had total assets of 16.75 trillion yuan, 25 times as much as in 2002, and the premium income reached 3.658 trillion yuan, 12 times as much as in 2002, making it the third largest insurance market in the world. From a perspective of absolute scale alone, the development level of China's financial system has already been among the world's leading.

\section{Table 1 China's Top companies Listed in Worldwide Top 500 in 2017}

This table lists the Chinese companies among the global 500 companies. Columns (1) and (2) show the rank and name of companies. Column (3) shows the operating incomes of firm. Column (4) shows the registered city of firms.

\begin{tabular}{|c|c|c|c|}
\hline Rank & Corporate Name & Operating Income ( million dollar) & City of Headquarters \\
\hline 22 & Industrial and Commercial Bank of China Limited & 147675.1 & Beijing \\
\hline 28 & China Construction Bank Corporation & 135093.3 & Beijing \\
\hline 38 & Agricultural Bank of China Limited & 117274.9 & Beijing \\
\hline 39 & Ping An Insurance (Group) Company of China & 116581.1 & Shenzhen \\
\hline 42 & Bank of China Limited & 113708.2 & Beijing \\
\hline 51 & China Life Insurance (Group) Company & 104818.2 & Beijing \\
\hline 114 & The People's Insurance Company (Group) of China Limited & 66731.9 & Beijing \\
\hline 139 & An Bang Insurance group & 60799.8 & Beijing \\
\hline 171 & Bank of Communications & 52989.6 & Shanghai \\
\hline 216 & China Merchants Bank & 44551.8 & Shenzhen \\
\hline 230 & Industrial Bank & 42621.6 & Fuzhou \\
\hline 245 & Shanghai Pudong Development Bank & 40688.7 & Shanghai \\
\hline 251 & China Min sheng Bank & 40234.3 & Beijing \\
\hline 252 & China Pacific Insurance & 40192.7 & Shanghai \\
\hline 329 & China Everbright Group & 32460.5 & Beijing \\
\hline 411 & Cathay Life Insurance Company & 26291.7 & Taipei \\
\hline 497 & New China Life Insurance Company Limited & 21795.7 & Beijing \\
\hline
\end{tabular}

The rapid development of China's virtual economy may have an extrusion effect on the real economy. Virtual economy is generally defined as "virtual assets" and a series of derivative concepts (Cochrane, 2005; Bhaduri et al., 2006; Baur, 2012; Nazir and Liu, 2016). Given the current social situation, there are more types and more complex relationships in the virtual economy (Jokipii and Monnin, 2013). According to a researcher named $\mathrm{Wu}$, virtual economy and real economy are attractive to money, and this kind of attraction has an unsymmetrical characteristic, which shows that virtual economy and real economy do not shift to each other. Luo puts forward the concept of "loss of profit",and explains its internal causes and its deviation. The source of enterprise's development is mainly enterprise's profit. In the background of today's virtual economy expansion, enterprises put more profit into virtual economy, most of which are not beneficial to enterprise's development. In particular, there is the 
existence that the short board China's real economy cannot overcome.Mainly includes, firstly, our country enterprise technology content is low, enterprise is in the low of value chain, lacks the core competitive power; secondly, the Chinese entity enterprise lacks the own brand. On the whole, although there are many enterprises going abroad, there is still a lack of a brand group with international influence, which leads to our country's manufacturing capability and scale advantage cannot be transformed into the brand advantage of Chinese enterprises. In Interbrand's list of the top 100 global brands, Huawei was the only Chinese brand by 2014. Huawei and Lenovo were the only Chinese companies to list the top 100 by 2017. China urgently needs to achieve the full expansion of corporate brands from point to line, and from line to surface.

In sum, China's real economy is facing severe challenges and unprecedented pressure. Because of the inherent fragility of the real economy, the effect of the negative impact of the virtual economy is deepened. Under the premise of the current rapid expansion of the virtual economy, whether China's virtual economy has already formed a squeeze on the real economy of our country has yet to be tested by our next empirical analysis.

\section{VARIABLES AND METHODS}

\section{(1) Variables}

In order to analyze the relationship between China's virtual economy and real economy, this paper takes 1992 Q1-2017 Q9 as sample interval and selects the corresponding variables to describe the characteristics of real economy and virtual economy respectively, in which the real economy uses the growth rate of real GDP year-on-year, while the virtual economy is difficult to measure (Gaddy and Lckes, 1999; Lehtiniemi, 2008). Researchers have used the characteristics of the capital market or real estate industry to express before. To a comprehensive measure of the operating state of the virtual economy, this paper selects bank variables (the balance of long-term loans and short-term loans), capital market variables (the yield of the Shanghai Composite Index, the price of the Shanghai Composite Index and the total market value of the whole market A shares), real estate variables (the real GDP growth rate of the real estate) and exchange rate market variables (the US dollar and yen to RMB exchange rate). After standardized treatment, PCA was used to reduce dimension, and the first principal component (contribution rate of $63 \%$ ) was selected as the factor of virtual economic variable. The result of principal component analysis shows that the total market value of A-share in fictitious economic variable factor is the biggest load, that is, the fictitious economic variable factor contains a lot of capital market information, followed by long-term loan balance and short-term loan balance of financial institution. The concrete variable selection and description is shown in Table 2.

Factor $1=$

0.4296*MV+0.3934*Index_price+0.1372*Index_ret-0.291 9*Exchange_japan-0.4058*Exchange_us_st-0.1666*GDP _house+0.4282*Loan_short+0.4253*Loan_long

Table 2: Variables

This table presents the variables used in the empirical analysis.

\begin{tabular}{|c|c|c|}
\hline Variable & Variable Name & Deal with the Variable \\
\hline \multicolumn{3}{|c|}{ (A) Real Economy Proxy } \\
\hline GDP & Real GDP & the growth rate of real GDP \\
\hline \multicolumn{3}{|c|}{ (B) Virtual Economy Proxies } \\
\hline Loan_long & Long-term Loans & the balance of long-term loans \\
\hline Loan_short & Short-term Loans & the balance of short-term loans \\
\hline Index_ret & Return on Index & the return on the Shanghai composite index \\
\hline Index_price & Price of Index & the price of the Shanghai composite index \\
\hline
\end{tabular}




\begin{tabular}{|c|c|l|}
\hline MV & Market Value & market value of total assets \\
\hline GDP_house & GDP of Real Estate & the real GDP growth rate of the real estate \\
\hline Exchange_us & Exchange Rate between RMB and US dollar & Exchange Rate between RMB and US dollar \\
\hline Exchange_japan & Exchange Rate between RMB and yen & Exchange Rate between RMB and yen \\
\hline
\end{tabular}

\section{(2) Models}

We use vector autoregressive method, which treat all variables in the system as endogenous variables. We specify a first-order VAR model as follows:

$$
z_{i t}=\alpha_{0}+\alpha_{1} z_{i t-1}+f_{i}+d_{c, t}+e_{t}
$$

The above mentioned $z_{i t}$ is a two-variable vector $\{G D P, V f 1\}$ GDP is gross domestic product, which is the representative of China's real economy. Nominal GDP can be reduced to real GDP by price index. The investment and appreciation of virtual assets are not included in the actual GDP. Vf1 represents virtual factor 1, this variable is our simulation of the virtual economy. Because the representation of the real economy in the existing literatures are mostly defined as GDP index, but there is still no definite conclusion about the virtual economy. The stock market is often used as the agent of the virtual economic variable in foreign literatures, but the author thinks that the indicators such as the broad money supply, the stock market value and the real estate price index can also be taken into account. Therefore, considering the robustness and authenticity of regression, this paper uses bivariate as the simulation of virtual variable, which is convenient to describe the virtual economy as a whole. The principal component analysis (PCA) method is adopted, we select the first two elements with higher principal component load as the agent of virtual factor 1. $e_{t}$ is a dimension vector for $k_{i}$, indicating the heterogeneous shock, assuming that the shock obeys the independent same distribution as the mean value of 0 and the covariance matrix is $\sum_{i i}$.

The impulse response function describes the innovative response of one variable to another variable in the system while keeping all other shocks equal to zero. However, because the actual variance-covariance matrix of the error cannot be diagonal, it is necessary to decompose the residual into orthogonal in order to isolate the impact of a variable in the system. The usual convention is to use a specific order and assign any correlation between the residuals of any two elements and the first variable in the sort. The identification hypothesis is that the earlier variables in the ordering affect both the following variables and the lag, and later variable only affects the previous variable in the lag.

Our model also takes country specific time virtual variables $d_{c, t}$ into account. These virtual variables are added to the model to capture specific country macro shocks that may affect all companies along the way. We eliminate this by subtracting the average of each variable calculated in each country in a year.

To analyze impulse response functions, we need to estimate their confidence intervals. Because the matrix of impulse response function is composed of estimated VAR coefficients, their standard errors need to be considered. We calculate the standard error of impulse response function and generate confidence interval. We compared the results of impulse response and considered the difference. Because our two samples are independent, the differential impulse response is equal to the difference in the impulse response (which also applies to the confidence interval of simulation).

\section{RESULTS}

\section{(1) Descriptive Statistics}

From China's economic real GDP growth rate quarterly and fictitious economic factors year-on-year trend, we can get some economic implications. Since reform and opening-up, China's high-speed economic development has created Chinese miracle one after another. After the broke out of financial crisis in 2008, China's economic development entered a new stage. The 
problems behind the long-term high-speed economic growth are gradually exposed. The financial crisis has caused the demand for Chinese exports from developed countries shrink sharply, which is undoubtedly a major blow to China's export-oriented economy, directly leading to China's net export share of GDP from $9 \%$ to less than $3 \%$, leading to a sharp decline in economic growth. GDP growth slowed sharply after reaching $12.1 \%$ in the first quarter of 2010. Until the third quarter of 2015, China's GDP growth rate fell below "7" for the first time. The growth rate was $6.9 \%$. It still hasn't reversed the downward trend. China's overall economic situation is grim. The economic growth rate has gradually declined, and caused problems such as overcapacity, real estate bubble,high leverage rate of government and state-owned enterprises. On the contrary, the trend of fictitious economic factors was relatively smooth before the financial crisis in 2008 . After the financial crisis, there was a sharp rise, and it still showed an upward trend within a certain period of time. In terms of the single performance of the capital market as a representative indicator of the fictitious economic factors, there was a big bull market in China's stock market from 2006 to 2007, mainly due to the abundant capital in the banking system, resulting in a large amount of capital flowing into the stock market and sufficient liquidity in the market, resulting in overheating of the market, pushing up the market index, The Shanghai Composite Index is as high as 6,000 points at one point. Investors use the form of "leverage" to increase the allocation of financial assets. Funds from the real economy flow to the virtual economy. with the bursting of the bubble, the market collapse phenomenon of "thousands of stocks stop" appears and so on. The economy was hit hard. In short, from the trend of virtual economy and real economy (Figure1), we find that the two trends appear obvious deviation, with a typical virtual-real deviationcharacteristics.

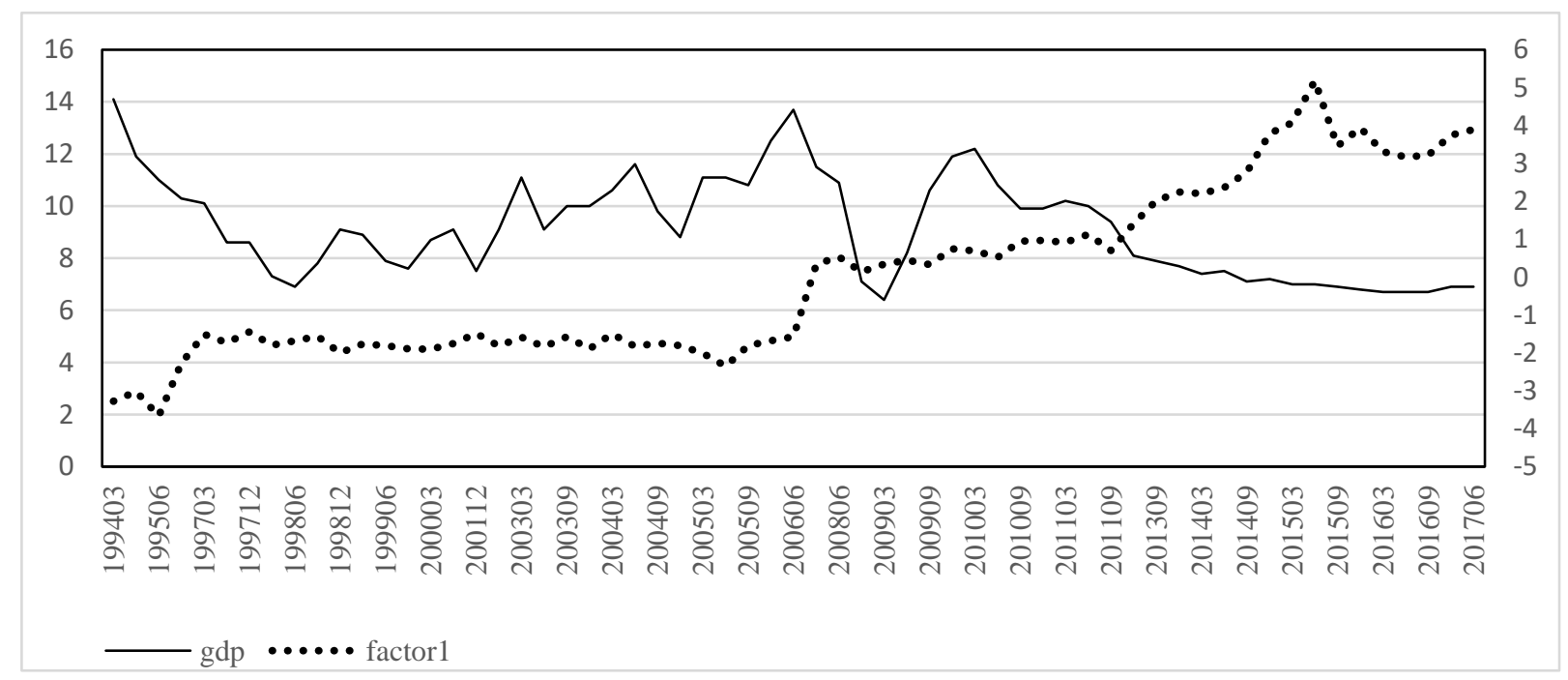

Fig.1: Trends of Real GDP and Virtual Economy (factor1)

(2) Empirical Results Analysis

Vector autoregressive model regards all variables as endogenous variable system, and the impact of unit variation of endogenous variable on other variables can be analyzed by impulse response diagram. First, the delay order is selected on the basis of determining variables (real economic variables and fictitious economic factors), then the first-order lag is optimal according to AIC, HQIC and
SBIC criteria, then the vector autoregressive model is estimated, and finally the impulse response is estimated, and the impact of the unit change of variables on other variables is analyzed.

The result of Fig. 2(A) shows that the impact of virtual economy on real economy is negative, which is obvious in the first two quarters, and it continues, be negative obviously. The "prosperity" of virtual economy 
will lead to a certain recession of real economy, which indicates that the side-effect of "off-real to virtual" on real economy is quite significant. On the contrary, according to the result of Fig. 2(B), the unit change of real economy has negative effect on virtual economy in a short time, but has no significant effect in the long term. In a word, the real economy has a significant downward trend in the face of the impact of the virtual economy, that is, the virtual economy has an obvious "extrusion effect" on the real economy, which inhibits the development of the real economy, while the virtual economy does not respond obviously to the impact of the real economy and has obvious self-circulation characteristics.
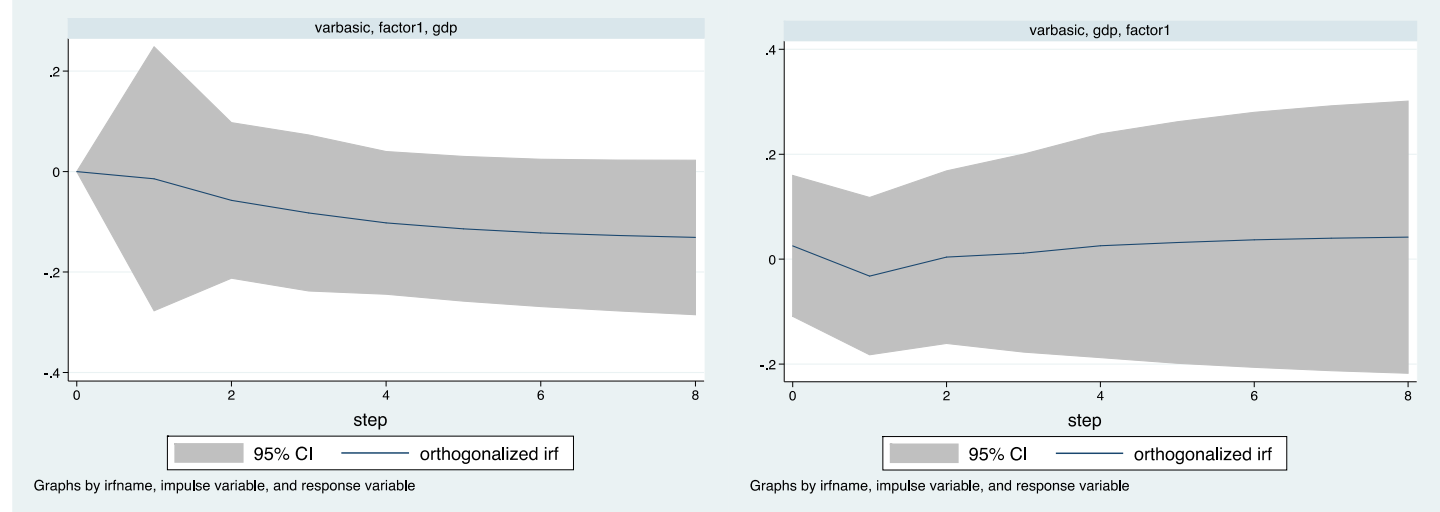

Fig.2: Impulse Response Diagram

\section{CONCLUSION AND SUGGESTIONS}

In this paper, the vector autoregressive model is used to analyze the relationship between virtual economy and real economy. The empirical results show that the virtual economy has a negative effect on real economy impact, and the "prosperity" of virtual economy leads to a certain recession on real economy, which indicates that the "de-realisation" of capital has a significant side effect on real economy. The unit change of real economy has a negative effect on fictitious economy in a short time, but has no significant effect in a long time. This indicates that the excessive development of fictitious economy will result in the deviation from real economy growth and the serious imbalance of industrial structure, which is also the internal root of the extruding effect of fictitious economy on the real economy. When a virtual economy loses the support of real economy, the emergence of economic crisis is the inevitable response of the market, and the post-crisis economic recovery process will be relatively slow, because it involves the restructuring of the industrial structure.
In view of China's current market situation, the proper development of virtual economy is beneficial to the real economy, the current transformation and upgrading of China's industry needs the driving role of virtual economy, the proper development of virtual economy can promote the development of real economy, can help Chinese enterprises get out of the difficulty of transformation quickly. The negative effects of the US financial crisis and the European debt crisis have been magnified, and many countries are suspect about the development of virtual economy. But the research of this paper shows that as long as the virtual economy development is controlled to a certain level, the virtual economy development can promote the real economy growth, at the same time, it can also promote the transformation and upgrading of the industrial structure.

\section{REFERENCES}

[1] Baur, D. G. (2012). Financial contagion and the real economy. Journal of Banking \& Finance, 36(10), 2680-2692. 
[2] Bhaduri, A., Laski, K., \&Riese, M. (2006). A model of interaction between the virtual and the real economy. Metroeconomica, 57(3), 412-427.

[3] Cochrane, J. (2005). Financial markets and the real economy (No. w11193). National Bureau of Economic Research.

[4] Gaddy, C., \& Ickes, B. W. (1999). Stability and disorder: An evolutionary analysis of Russia's virtual economy.

[5] Jokipii, T., \& Monnin, P. (2013). The impact of banking sector stability on the real economy. Journal of International Money and Finance, 32, 1-16.

[6] Lehtiniemi, T. (2008). Macroeconomic indicators in a virtual economy.

[7] Nazir, M., \& Lui, C. S. M. (2016). A brief history of virtual economy. Journal for Virtual Worlds Research, 9(1). 